\title{
ARCTIC ANTHROPOLOGY
}

RETURN THIS AD AND RECEIVE A FREE SAMPLE ISSUE.

Published: $2 / \mathrm{yr}$.

ISSN: 0066-6939

Devoted to the study of Old and New World northern cultures and peoples. Archaeology, ethnology, ethnohistory, linguistics, human biology and other related fields are represented.

Rates:

Individuals (must pre-pay): $\$ 31 / \mathrm{yr}$.

Institutions:

$\$ 87 / \mathrm{yr}$.

Foreign postage: $\quad \$ 8 / \mathrm{yr}$.

Airmail: $\$ 11 / \mathrm{yr}$.

We accept MasterCard and VISA. Canadian customers please remit $7 \%$ Goods and Services Tax.

Please write for a free back issue list:

Journal Division, University of Wisconsin Press, 114 North Murray Street, Madison, WI 53715 USA

Or call, 608-262-4952, FAX 608-265-5277 


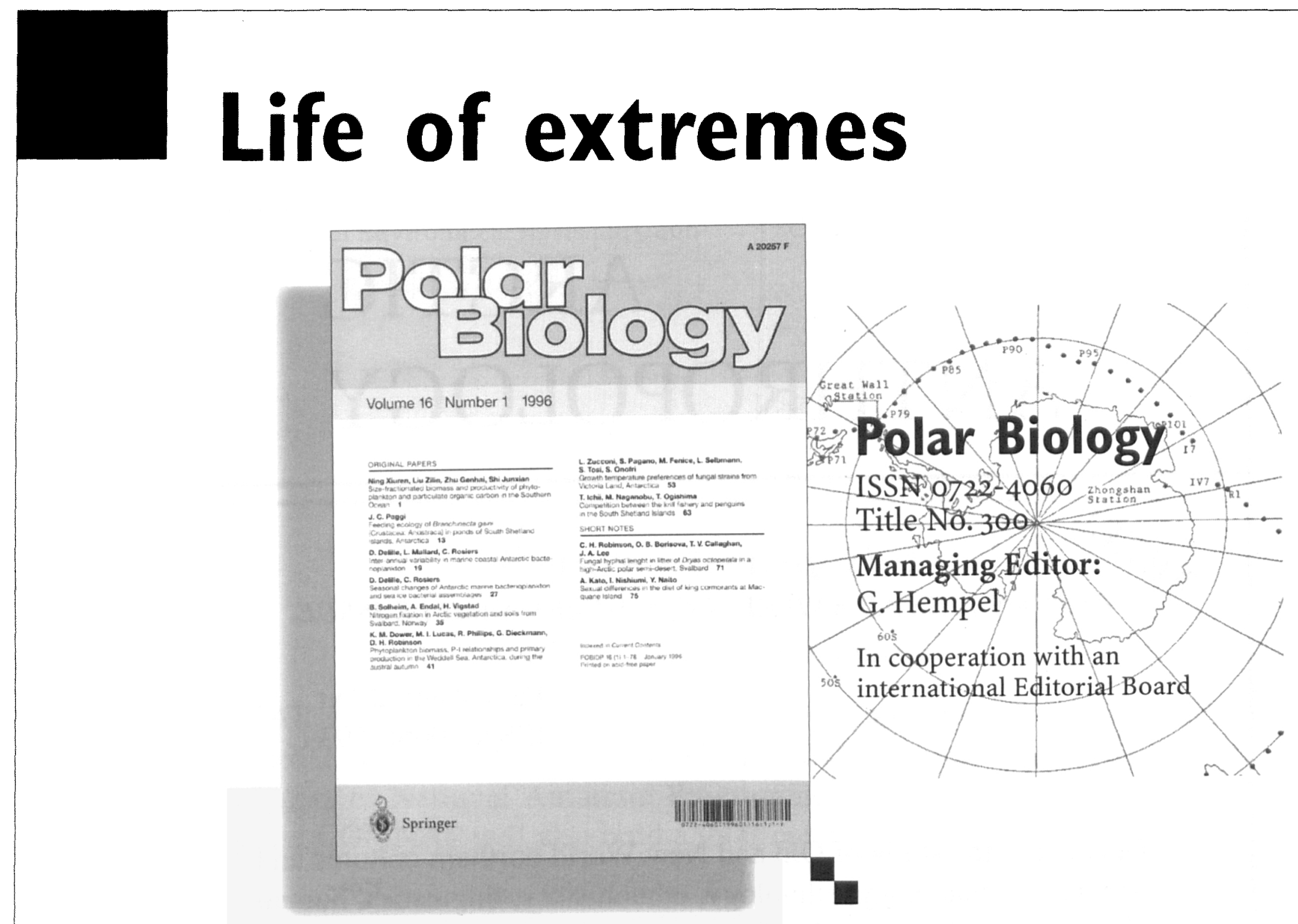

Polar Biology is not only the focal point for scientists working in polar regions but also attracts the interest of those working in general biology, ecology, and physiology as well as in oceanography and climatology related to polar life. The journal presents results of all kinds of studies in plants, animals and microorganisms of marine, limnic and terrestrial habitats of Artic and Antarctic regions.

Topics covered include:

- Life history

- Ecology of organisms and communities

- Morphology and taxonomy

- Distribution, abundance and biogeography

- Dynamics of populations

- Physiology of growth, metabolism and reproduction

- Behaviour and sensory physiology

- Ecosystem studies.

\section{Subscription information}

for 1996:

Volume 16 (8 issues)

DM 1268,-* 


\section{Copying}

Polar. Record is registered with the Copyright Clearance Center, 222 Rosewood Drive, Danvers, MA 01923, USA. Organizations in the USA that are also registered with the CCC may copy material (beyond limits permitted by sections to multiple copies for promotional or commercial pur $C C C$ of the per copy fee of $\$ 11.00$. This consent does not extend Copyright Licensing Agency may also copy material subject to the usual $0032-2474 / 96$. Organizations authorized by the be sought from the Cambridge or the American Braject the usual conditions. For all other use, permission should

\section{Back issues}

For vols $1-23$ inclusive apply to Bluntisham Books, Oak House, East Street, Bluntisham, Huntingdon PE17 3LS, UK.
For vols 24 onward apply to Cambridge University Press, UK or USA.

Advertising

For details apply to the Editor or to the publishers.

CAMBRIDGE UNIVERSITY PRESS

Published by the Press Syndicate of the University of Cambridge

The Pitt Building, Trumpington Street, Cambridge CB2 1RP, UK

40 West 20th Street, New York, NY 10011-4211, USA

10 Stamford Road, Oakleigh, Melbourne 3166, Australia

Printed in Great Britain at the University Press, Cambridge. 


\section{POLAR RECORD}

VOLUME 32 NUMBER 183 OCTOBER 1996

\section{CONTENTS}

ARTICLES

Early photographers of the Arctic. Douglas Wamsley and William Barr $p 295$

Orographic clouds in north Victoria Land from AVHRR images. Giuseppe Zibordi and Massimo Frezzotti p 317 Frobisher's 1578 voyage: early eyewitness accounts of English ships in Arctic seas. James McDermott p 325 Identifying national interests in Antarctica: the case of Canada. Peter J. Beck p 335

Pingo growth ages in the delta area, Adventdalen, Spitsbergen. Kenji Yoshikawa and Toshio Nakamura p 347

\section{NOTES}

The Northern Sea Route, 1995. Lawson W. Brigham and Terence Armstrong p 353

Non-government aircraft in the Antarctic 1995/96. Charles Swithinbank p 355

POLAR PROFILE

Gerald S. Doorly. Dorothy Freed p 357

\section{REVIEWS}

Franz Josef Land. Susan Barr (editor). Beau Riffenburgh p 361

Dynamics and modelling of ocean waves. G.J. Komen, L. Cavaleri, M. Donelan, K. Hasselmann, S. Hasselmann, and P.A.E.M. Janssen. Peter Wadhams p 362

The night side of Dickens: cannibalism, passion, necessity. Harry Stone. Richard C. Davis p 363

Swansea's Antarctic explorer: Edgar Evans, 1876-1912. G.C. Gregor. Geoffrey Hattersley-Smith p 364

An Arctic voyage to Baffin's Bay and Lancaster Sound in search of friends with Sir John Franklin. Robert A.

Goodsir. James M. Savelle p 365

Antarctica offshore: a cacophony of regimes? R.A. Herr (editor). Peter J. Beck p 366

Of dogs and men: fifty years in the Antarctic. Kevin Walton and Rick Atkinson (editors). John A. Heap p 367

Critical issues in editing exploration texts. Germaine Warkentin (editor). lan R. Stone p 368

People of the bays and headlands. John C. Kennedy. Mark Nuttall p 369

Protecting the Antarctic environment: Australia and the minerals convention. Lorraine Elliott. Stuart Kaye p 370

The Antarctic voyage of HMAS Wyatt Earp. Phillip Law. David Lyons p 371

My life of adventure. Norman D. Vaughan with Cecil B. Murphey. lan Higginson p 371

The ice-age history of Alaskan national parks. Scott A. Elias. Martin J. Siegert p 372

\section{OBITUARIES}

Count Eigil Knuth p 373

The Rev Harold Duncan p 374

John Blyth p 374

Guttorm Jakobsen p 375

\section{CORRESPONDENCE}

Dog driving in the Arctic. Andrew Croft p 376

\section{IN BRIEF}

United Nations Environment Programme selects ICAIR p 377

Polar tourism conference p 377

SPRI 1996 Christmas cards p 378

\section{SCAR BULLETIN No 123}

Stations of SCAR Nations operating in the Antarctic, Winter 1996 p 379

Address List of SCAR Executive Committee, Honorary Members, National Committees, Delegates and Chief Officers $p 382$

\section{CAMBRIDGE UNIVERSITY PRESS}

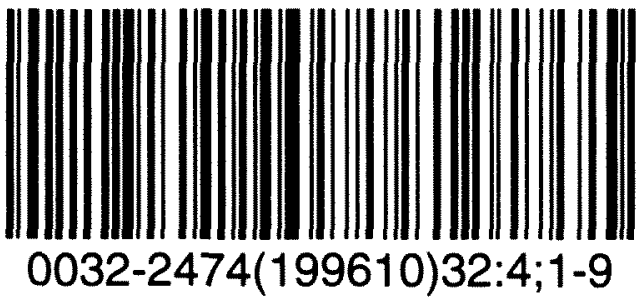

